\title{
Cardiac Lead Insulation Failure
}

National Cancer Institute

\section{Source}

National Cancer Institute. Cardiac Lead Insulation Failure. NCI Thesaurus. Code C99932.

Insulation failure manifests as low lead impedance either absolutely (below

manufacturer's product specifications) or by a significant decrease from previously

stable chronic values. (ACC) 